\author{
Published by Avanti Publishers
}

The Global Environmental

Engineers

ISSN (online): 2410-3624

\title{
Energy and Environmental Benefit of Solar Charging System for Charging Auto-Rickshaw in Developing Countries
}

\author{
Md. Uddin", A.Z.M. Rahman and Sumon Mondol \\ Department of Mechanical Engineering, Rajshahi University of Engineering and Technology, Rajshahi-6204, Bangladesh
}

\section{ARTICLE INFO}

Article Type: Research Article

Keywords:

Energy

Auto-rickshaw

Developing country

Solar charging system

Environmental impact

Timeline:

Received: October 22, 2021

Accepted: November 25, 2021

Published: December 24, 2021

Citation: Uddin M, Rahman AZM, Mondol S. Energy and Environmental Benefit of Solar Charging System for Charging Auto-Rickshaw in Developing Countries. Glob. Environ. Eng. 2021; 8: 46-54.

DOl: https://doi.org/10.15377/2410-3624.2021.08.4

\begin{abstract}
The energy crisis and environmental impact are the major concern mf the present world. Three-wheeler auto-rickshaw becoming an important passenger transport vehicle in a developing country which are indirectly powered by the grid electricity through the batteries. Such vehicle consumes significant grid energy during charging which increases the load in the national grid and put extra stress on the electrification in line with the environmental impact. This paper investigated the existing facilities for charging auto-rickshaw in Bangladesh and designed a proposed solar charging model as a replacement based on the existing model. Then the energy and environmental benefit were estimated to reflect the significance of the proposed model and contribution in the context of the global energy crisis and environmental impact. The investigation found that the daily energy consumption is $290 \mathrm{kWh}$ for a charging station capacity of 30 auto-rickshaws which is significant. The proposed solar model is designed to meet this demand offset. The environmental analysis showed that the proposed model can offset $\mathrm{CO}_{2}, \mathrm{CH}_{4}$, and $\mathrm{NOx}$ emissions by $54 \mathrm{tCO}_{2} \mathrm{eq}, 40 \mathrm{kgCO}$ eq, and 60 $\mathrm{kgCO}_{2}$ eq per year respectively of which the contribution of $\mathrm{CO}_{2}$ is significant. Further research could be focused on the economic and financial analysis in-depth to promote the proposed model.
\end{abstract}

*Corresponding Author

Email: shazib0397@gmail.com

Tel: +61470251883

(C) 2021 Uddin et al. Published by Avanti Publishers. This is an open access article licensed under the terms of the Creative Commons Attribution Non-Commercial License which permits unrestricted, non-commercial use, distribution and reproduction in any medium, provided the work is properly cited. (http://creativecommons.org/licenses/by-nc/4.0/) 


\section{Introduction}

Three-wheeler auto-rickshaws became very popular in developing countries in short-distance travel. They are low transportation cost, comfortable, and do not create any environmental pollution directly as the other types of conventional vehicles which consume fossil fuels. In the last few years, the amount of three-wheeler autorickshaws has increased rapidly, around $60 \%$ in Bangladesh and neighboring countries [1]. Those auto-rickshaws need electrical energy to drive. The lead-acid batteries are usually placed in these auto-rickshaws and are usually charged by grid electricity. Such grid electricity is produced by burning mostly fossil sources and emitting serious pollutants into the environment. So in the broad sense of view although these vehicles do not affect the environment directly they cause environmental pollution indirectly. The daily electricity consumption by the autorickshaw is significant which reflects such vehicles are a consumer of significant electricity of the generation [2].

The developing countries achieved a significant level of technological advancement over the last 15 years [3]. The technological advancement in low and middle-income nations has increased rapidly compared to the highincome countries. The adaption of technology by developing countries reflected the insightful effect on the country's economies through reducing the production cost, establishing the standards of quality, and establishing communication between individuals from a distance. The countries are moving towards renewables as part of the industrialization process. Because the renewables are clean, enhance energy security and respond to the essential of economic [4].

Solar photovoltaic is a renewable energy technology getting high priority in developing countries due to their favorable location for solar utilization. The photovoltaic panel can be utilized for charging the auto-rickshaw batteries which could be one of the ways to mitigate the use of countries' grid electricity is the focus of this paper. In this regard, a solar charging station utilizing the solar photovoltaic panel is proposed.

There are limited numbers of research papers based on three-wheeler auto-rickshaw found online. Mankar and Ghute, 2015 [5] investigated a simulation study on the charging and discharging performance of a battery using a PV panel and electric motor to drive the electric vehicle. They found that the battery is successfully charged and to drive the vehicle. The electric vehicle is more cost-effective than a conventional fuel vehicle. Ahmed et al., 2015 [6] constructed and investigated the performance of PV-operated cycle rickshaws. They found that the maximum speed of the rickshaw found to $15-25 \mathrm{~km} / \mathrm{h}$ with a load of $250 \mathrm{~kg}$. Full charging time is $3.5-4$ hours and the miles run by full charge is $35-45 \mathrm{~km}$. Rian and Rahman, 2014 [7] investigated the feasibility study of battery-operated auto-rickshaw and the effect on the socio and environmental aspects. They found that the energy consumption by auto-rickshaw is 8-11 kWh per day. Operating cost is lower than that of fuel-operated conventional auto rickshaw. The operating cost and $\mathrm{CO}_{2}$ emission for battery-operated auto-rickshaw are lower than the fuel-operated auto rickshaw. Rana et al., 2013 [8] investigated the effect of charging on local towns and its contribution to reduce transport emissions. Around $5.9 \%$ of the daily electricity demand of the town is consumed for auto rickshaw battery charging where the recharge demand is $17 \%$. A total of 11,208 batteryoperated auto-rickshaws consume $82.90 \mathrm{MWh}$ of electricity per day to be recharged. Significant direct emissions could be reduced by these vehicles. Shaha and Uddin, 2013 [9] studied the feasibility of hybrid charging of batteryoperated auto-rickshaw using battery charger, rooftop installed a solar panel and regenerative technique. Advanced vehicle simulator software is used for the analysis. Energy consumption can be saved by $20 \%$ using a regenerative way for low-speed conditions. The vehicle mileage increased by 1.5 hours and driving range of 35 to $40 \mathrm{~km}$ using the solar panel. A hybrid energy storage system increases vehicle performance and efficiency. Rahim et al., 2013 [10] investigated the positive socio-economic impact, drawbacks, energy consumption, comparison with fuel-operated vehicles, trends of the maintenance cost, charging time, and vehicle performance with the age. They found that per km running cost is lower with passenger comfort. The high initial investment, maintenance cost, replacement cost are the barrier to promoting such vehicles. The charging time is increased and performance is decreased with lifetime. Nunes et al., 2016 [11] reviewed a comprehensive overview and framework of the solar parking lot, review of the state of the art, challenges, and opportunities to develop and implement the concept is studied. Solar electricity generated parking space is enough to the electric car by 75$100 \%$ depending on the availability of solar radiation. Smart chargers using optimization can adjust to deliver the energy to cars and the grid. Financial, economic, and revenue analysis is required to implement such a system. 
The studies reported above are reflected for the moving solar panel installed on the rooftop of the autorickshaw. The availability of continuous sunlight is the barrier of such a system studied which could be overcome by installing a stationary renewable charging station. In addition, environmental pollution analysis for such a system seems missing in the previous studies. This paper fulfilled those research gaps. This study aims to design a proposed solar charging station for the auto-rickshaws and investigate the potential energy and environmental benefit.

\section{Existing Charging Facility}

This section presented the status of the existing charging system (base case). Based on the existing analysis the proposed charging facility is presented in the following section. In the existing system, the grid electricity is connected to the charging station and the auto-rickshaw recharges from the station. The typical schematic of the existing charging system is shown in Figure 1. The details of the existing charging station have been collected inside one of the divisional cities of Bangladesh. The data are collected through measures and questionnaires wherever applicable for the same capacity station. The details of the charging station are given in Table 1.

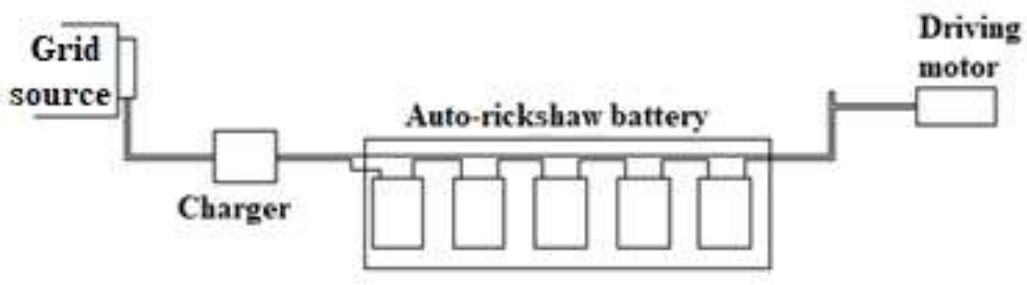

Figure 1: Existing charging system layout.

The lead-acid type $12 \mathrm{~V}, 140-160 \mathrm{amp}$ battery is usually installed in the autorickshaw. The time required to fully charge is 8-10 hours, the distance traveled per full charge is $150 \mathrm{~km}$ and the energy consumed per full charge is 10 $\mathrm{kWh}$ measured from the charging station. The charger input is $220 \mathrm{~V}, 4.95 \mathrm{~A}$ and the output is $60 \mathrm{~V}, 14 \mathrm{~A}$ measured from the station.

Table 1: Details of the existing charging station.

\begin{tabular}{|c|c|c|c|c|c|c|c|}
\hline \multirow{2}{*}{$\begin{array}{l}\text { No of } \\
\text { Station }\end{array}$} & \multirow{2}{*}{$\begin{array}{l}\text { Name of } \\
\text { Charging } \\
\text { Station }\end{array}$} & \multirow{2}{*}{$\begin{array}{c}\text { No. of } \\
\text { Autorickshaw } \\
\text { Capacity at a Time }\end{array}$} & \multicolumn{2}{|c|}{$\begin{array}{l}\text { Time Required to Full Charge } \\
\text { Per Autorickshaw (hr) }\end{array}$} & \multirow{2}{*}{$\begin{array}{l}\text { Avg. Time } \\
\text { to Full } \\
\text { Charge (hr) }\end{array}$} & \multirow{2}{*}{$\begin{array}{l}\text { Cost Per } \\
\text { full Charge } \\
\text { (BDT) }\end{array}$} & \multirow{2}{*}{$\begin{array}{l}\text { Monthly Electricity } \\
\text { Bill Paid by the } \\
\text { Station (BDT) }\end{array}$} \\
\hline & & & At New Condition & At Old Condition & & & \\
\hline 1 & NM & 30 & $8-9$ & 10 & \multirow{5}{*}{9} & 160 & \multirow{5}{*}{$85000-90000$} \\
\hline 2 & MM & 30 & $8-8.5$ & 10 & & 160 & \\
\hline 3 & SM & 30 & 8 & 10 & & 160 & \\
\hline 4 & $\mathrm{TM}$ & $28-30$ & $8-9$ & 10 & & 160 & \\
\hline 5 & $\mathrm{KL}$ & 30 & 8 & 10 & & 160 & \\
\hline
\end{tabular}

Source: Measured and field survey.

The voltage and current are measured during the charging to quantify the energy consumption by the battery for both new conditions and old conditions. The currents are measured at the inlet and the exit of the charger to find out the actual energy consumption by the battery. The details of the measured data are given in Table $\mathbf{2}$.

\section{Prospective Charging Facility}

The proposed charging facility emphasized the replacement of conventional grid power by solar power in the charging station for the number of autorickshaws accommodated is 30 . To design a solar-powered charging 
station the components required are a solar panel, controller, inverter, battery, wiring, and support frame. The layout of the proposed charging system is shown in Figure $\mathbf{2}$.

Table 2: The current and voltage details for the battery.

\begin{tabular}{|c|c|c|c|c|c|}
\hline Battery Condition & Obs. No. & $\begin{array}{l}\text { Wall to Charger } \\
\text { Inlet Current (A) }\end{array}$ & Average (A) & $\begin{array}{l}\text { Charger Exit to } \\
\text { Battery Current (A) }\end{array}$ & Average (A) \\
\hline \multirow{14}{*}{ New } & 01 & 5.1 & \multirow{14}{*}{$\begin{array}{c}5.79 \\
(220 \mathrm{~V})\end{array}$} & 15 & \multirow{14}{*}{$\begin{array}{l}16.68 \\
(60 \mathrm{~V})\end{array}$} \\
\hline & 02 & 6.5 & & 18 & \\
\hline & 03 & 6 & & 18.4 & \\
\hline & 04 & 6.5 & & 18.4 & \\
\hline & 05 & 5.2 & & 15.6 & \\
\hline & 06 & 6.2 & & 17.3 & \\
\hline & 07 & 7.2 & & 18.7 & \\
\hline & 08 & 5 & & 15.1 & \\
\hline & 09 & 6.5 & & 17.5 & \\
\hline & 10 & 6.5 & & 17.6 & \\
\hline & 11 & 4.8 & & 15.6 & \\
\hline & 12 & 5.5 & & 17.5 & \\
\hline & 13 & 5.5 & & 15.5 & \\
\hline & 14 & 4.5 & & 13.3 & \\
\hline \multirow{6}{*}{ Old } & 01 & 2.5 & \multirow{6}{*}{$\begin{array}{c}3 \\
(220 \mathrm{~V})\end{array}$} & 7 & \multirow{6}{*}{$\begin{array}{c}8 \\
(60 \mathrm{~V})\end{array}$} \\
\hline & 02 & 3.2 & & 8.6 & \\
\hline & 03 & 1.7 & & 5.7 & \\
\hline & 04 & 2.1 & & 6.2 & \\
\hline & 05 & 4.3 & & 10.5 & \\
\hline & 06 & 4.2 & & 10 & \\
\hline
\end{tabular}

Source: Measured in the station.

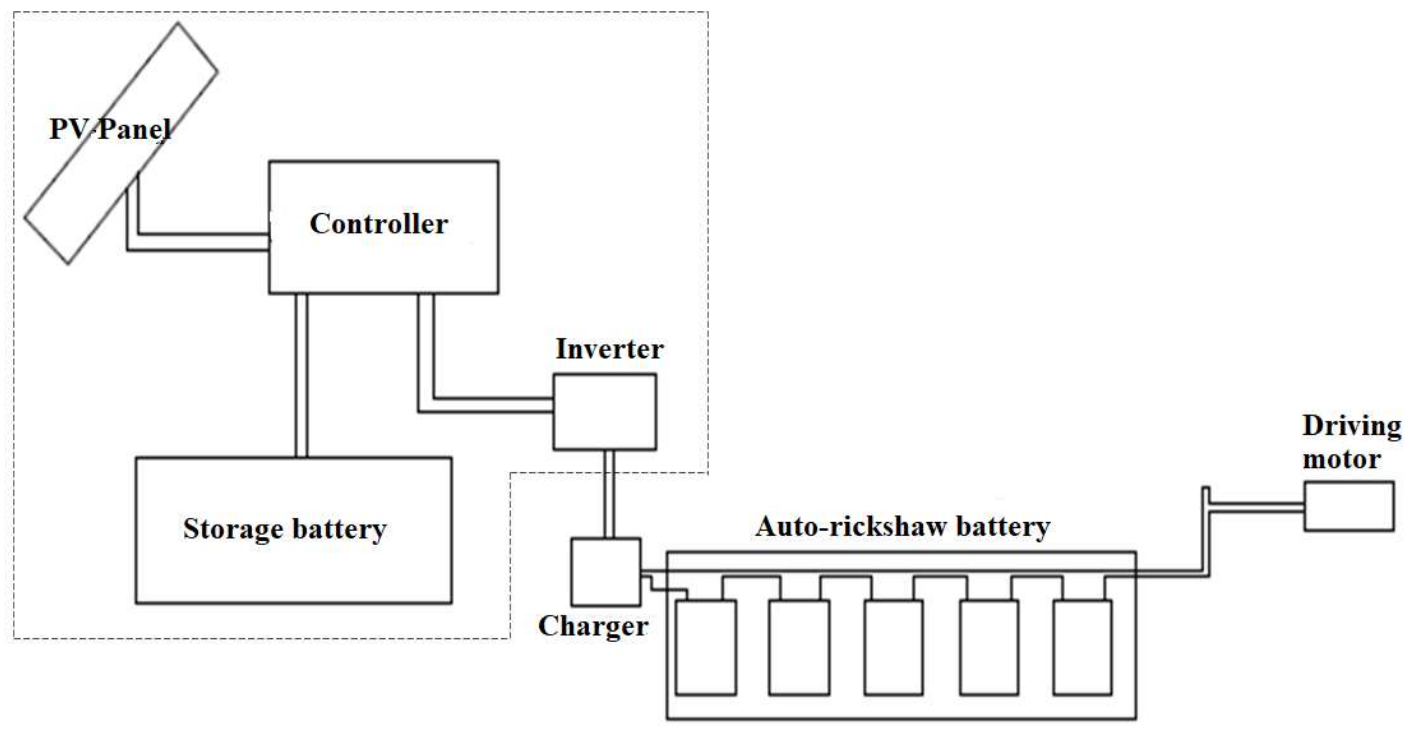

Figure 2: Proposed charging system design layout. 
In this layout, the existing grid power source is replaced by four main components. The solar PV panel generates electricity using solar radiation which is rooftop installation. The controller monitors the battery condition and charging update and regulates the input to avoid overcharging. The storage battery is a backup source that stored the solar energy in the daytime and delivers it at night-time or the day having low solar radiation. The inverter converts the direct current (DC) from the battery to alternating current (AC) suitable for the load.

The design calculation showed that the area required by the panel for such a capacity station is more than the area required for parking 30 auto-rickshaws and charging setup. The rest of the space is proposed for the retail shops. The floor layout is shown in Figure 3.

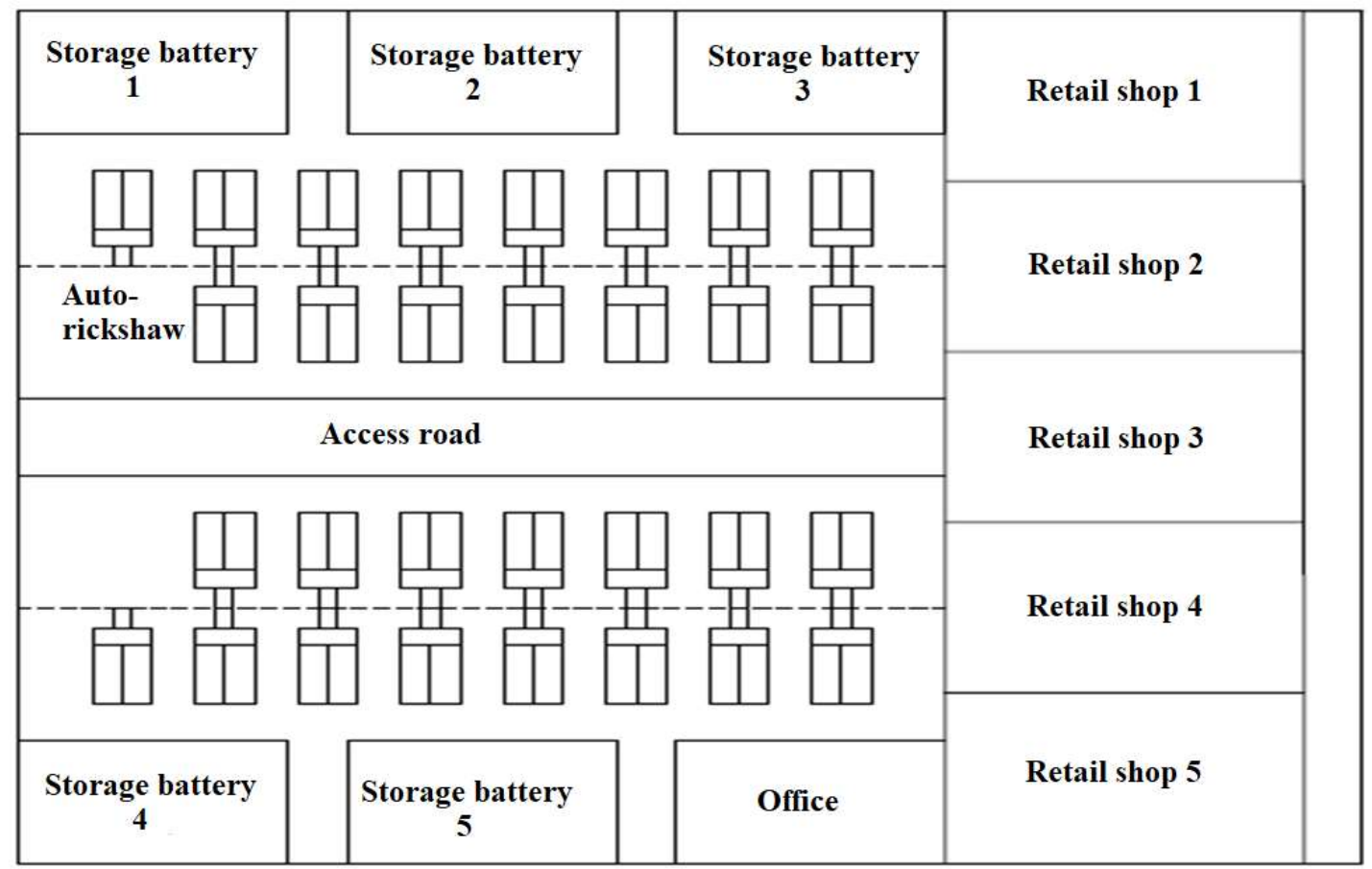

Figure 3: The floor layout of the solar charging station.
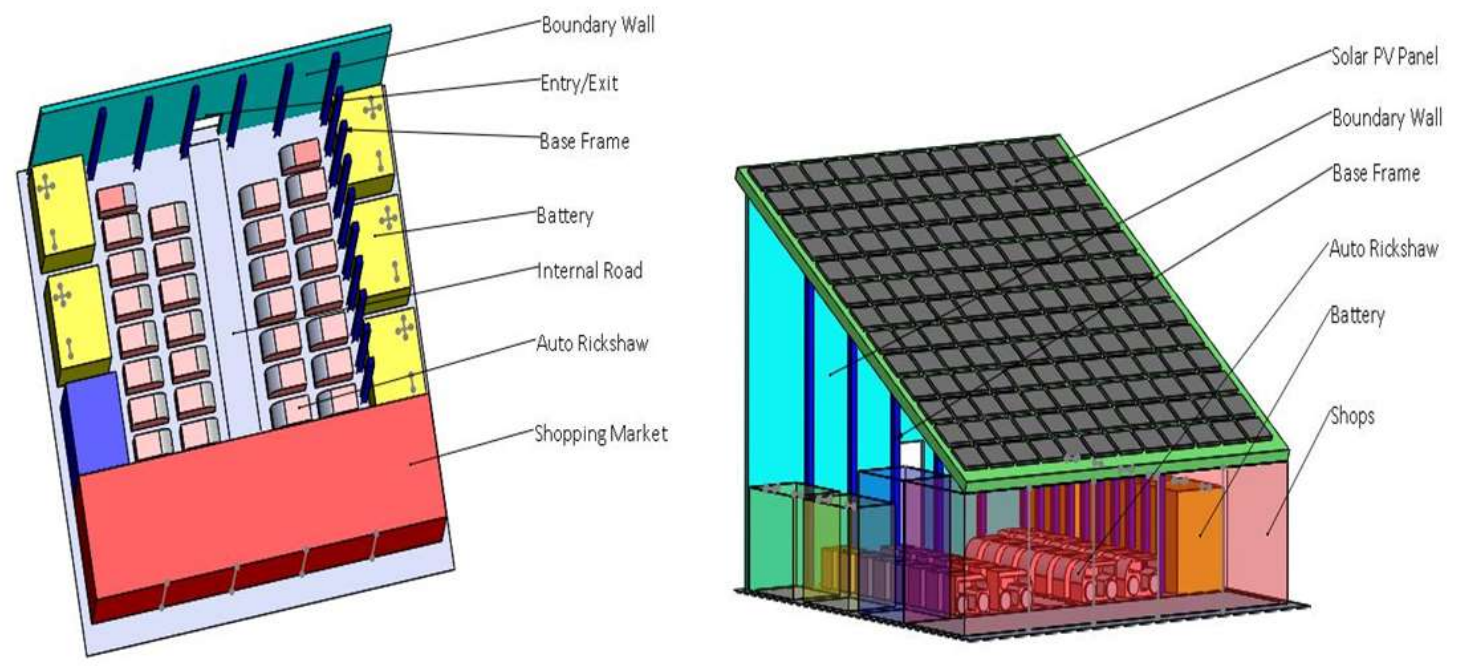

Figure 4: The 3D view of the charging station. 


\section{Design Calculations}

This section describes the calculation behind the design of a solar charging station for charging auto-rickshaw.

\section{Daily Energy Required for Charging}

The daily energy required for the charging can be computed as follows.

The voltage at the charger exit $\mathrm{V}=60 \mathrm{~V}$

Current at the charger exit $\mathrm{I}=16.68 \mathrm{~A}$

The battery input energy for 30 auto rickshaws per day= VI $\times$ No of hours to full charge/day $\times$ no. of autorickshaw/day

$=60 \times 16.68 \times 8 \times 30(\mathrm{Wh})$

$=240.19 \mathrm{kWh} /$ day

The system loss measured in the charger is $21 \%$

The daily energy required including system loss $=290 \mathrm{kWh} /$ day required to deliver by the solar panel to meet the charging demand for the station.

\section{PV Panel Required}

Assuming the panel generation factor for Bangladesh is 4.5 sunshine hour

The total watt peak (Wp) of the panel required $=290 \mathrm{kWh} / 4.5 \mathrm{hr}=64.44 \mathrm{~kW}$

The PV panel available in the local market medium size rating is $250 \mathrm{~W}_{\mathrm{p}}$.

The number of PV panels $=64.44 * 1000 / 250=258$ each of $250 \mathrm{~W}_{\mathrm{p}}$ rating.

\section{Land Required for PV Installation}

The land required for parking 30 auto-rickshaws is $1,100 \mathrm{~m}^{2}$.

The field survey shows that one $250 W_{p}$ PV panel dimension=1.956 m×0.992 m=1.94 $\mathrm{m}^{2}$.

The land required to install the PV panel=258 $\times 1.94=500 \mathrm{~m}^{2}=22.35 \mathrm{~m} \times 22.35 \mathrm{~m}$ which is around $50 \%$ of the parking land consumption.

\section{Storage Required}

The daily energy required $=290 \mathrm{kWh} /$ day

Nominal battery voltage $=12 \mathrm{~V}$

Days of autonomy $=1$ days

The battery capacity can be computed by the following expression [12].

$$
\begin{aligned}
\text { Battery capacity } & =\frac{\mathrm{Wh} / \text { day } \times \text { days of autonomy }}{\text { efficiency } \times \text { depth of discharge } \times \text { nominal battery voltage }} \\
& =\frac{290 \times 1000 \times 1}{0.85 \times 0.6 \times 12}=47,385 \mathrm{Ah}
\end{aligned}
$$

Where battery efficiency is 0.85 , the depth of charge is 0.6 .

So the battery should be rated as $12 \mathrm{~V}, 47,385$ Ah for 1-day autonomy.

The battery capacity is available in the market $=130 \mathrm{Ah}$ 
So with this rating, the number of batteries required

$$
\begin{aligned}
& =\frac{\text { Required battery capacity }(\mathrm{Ah})}{\text { Each battery capacity }(\mathrm{Ah})} \\
& =\frac{47,385}{130}=364 \text { each of } 12 \mathrm{~V}
\end{aligned}
$$

\section{Energy and Environmental Analysis}

\subsection{Energy in Terms of the Primary Form}

The charging station with a capacity of 30 auto-rickshaws requires daily energy demand is 290 kWh. This amount is supposed to meet from the grid as per existing facilities. If the transmission loss from the power plant to the supply feeder is $15 \%$ then the energy demand at the power plant raised to $333.5 \mathrm{kWh}$.

In Bangladesh, more than $90 \%$ of the country's generation comes from fossil sources of which $62 \%$ are from natural gas plants and 30\% are from oil-based plants [13]. In this regard, the breakdown of the energy demand is $207 \mathrm{kWh}$ from the natural gas-based plants and $100 \mathrm{kWh}$ from the oil-based plants. The contribution of the coal power plant is insignificant. If the average efficiency of the power plant is $38 \%$ then the energy demand in terms of primary form can be estimated as follows.

Primary energy for the gas power plant $=\frac{207 \mathrm{kWh}}{0.38}=544.73 \mathrm{kWh}=1961 \mathrm{MJ}$

Similarly, the primary energy for the oil-based power plant is $947 \mathrm{MJ}$. In terms of quantities of fuel, the requirement can be estimated as $42.63 \mathrm{~kg}$ natural gas and $22.0 \mathrm{~kg}$ oil per day.

\subsection{Emission and Environmental Impact}

The $\mathrm{CO}_{2}, \mathrm{CH}_{4}$, and $\mathrm{N}_{2} \mathrm{O}$ are the major components of the greenhouse gas emission which is released during the combustion of fossil fuels. The emission factor of these gases for stationary combustion is shown in Table $\mathbf{3}$.

Table 3: Emission factors for the stationary combustion [14].

\begin{tabular}{|c|c|c|c|}
\hline Fuel & $\mathbf{C O}_{\mathbf{~}}(\mathbf{k g} / \mathbf{M J})$ & $\mathbf{C H}_{4}(\mathbf{g m} / \mathbf{M J})$ & $\mathbf{N O}_{\times}$(gm/MJ) \\
\hline \hline Natural gas & 0.056 & 0.001 & 0.0001 \\
\hline Oil & 0.074 & 0.003 & 0.0006 \\
\hline Coal & 0.094 & 0.001 & 0.0015 \\
\hline
\end{tabular}

The quantities of the emissions can be estimated using Table $\mathbf{3}$ for the primary energy use demanded in the solar charging station given in Table 4. The quantities of the emissions are computed using the following expression.

Quantities emission $(\mathrm{kg})=$ Amount of estimated fuel $(\mathrm{kg} /$ day $) \times$ Energy content $(\mathrm{MJ} / \mathrm{kg})$

$$
\times \text { Emission factor }(\mathrm{kg} / \mathrm{MJ})
$$

Table 4: Quantities emission per day.

\begin{tabular}{|c|c|c|c|}
\hline Fuel & $\mathbf{C O}_{2}(\mathbf{k g})$ & $\mathbf{C H}_{4}(\mathbf{g m})$ & $\mathbf{N O}_{\mathbf{x}}(\mathbf{g m})$ \\
\hline \hline Natural gas & 109.8 & 1.96 & 0.196 \\
\hline Oil & 70.07 & 2.84 & 0.568 \\
\hline Total & 179.87 & 4.8 & 0.764 \\
\hline
\end{tabular}


If the station is energized from the grid supply then the daily $\mathrm{CO}_{2}, \mathrm{CH}_{4}$, and $\mathrm{NOx}$ emissions estimated are $179.87 \mathrm{~kg}, 4.8 \mathrm{gm}$, and $0.764 \mathrm{gm}$ respectively of which the contribution of $\mathrm{CO}_{2}$ is significant. If the 100 year GWP for the $\mathrm{CO}_{2}, \mathrm{CH}_{4}$, and $\mathrm{NO}_{\mathrm{x}}$ are 1, 28, and 265 [15] then the daily environmental impact can be estimated as 179.87 $\mathrm{kg} \mathrm{CO} 2 \mathrm{eq}, 134.4 \mathrm{gm} \mathrm{CO} 2 \mathrm{eq}$, and $202 \mathrm{gm} \mathrm{CO} 2 \mathrm{eq}$ for the $\mathrm{CO}_{2}, \mathrm{CH}_{4}$, and $\mathrm{NO}_{\mathrm{x}}$ respectively. Such an amount of daily environmental impact will be offset when the charging station will be energized by the solar system. If the number of days of solar utilization per year is 300 then the annual environmental impact can be estimated as $54 \mathrm{tCO}_{2} \mathrm{eq}$, $40 \mathrm{kgCO}_{2} \mathrm{eq}$, and $60 \mathrm{kgCO}$ eq for the $\mathrm{CO}_{2}, \mathrm{CH}_{4}$, and $\mathrm{NO}_{\mathrm{x}}$ respectively.

\section{Conclusions}

This paper emphasized the solar charging system for charging three-wheelers auto-rickshaw in the context of a developing country. The energy consumption of the existing charging facilities is measured and analyzed to discover the basis of proposed charging facilities. The proposed charging facilities design layout and necessary design calculations are presented. The energy and environmental emission offset by the proposed design facilities are studied. The result showed that the existing grid-connected charging station capacity of 30 auto-rickshaws consumes $290 \mathrm{kWh}$ energy per day which is significant. The proposed solar model is designed to meet this daily demand. The environmental analysis showed that the proposed model can reduce $\mathrm{CO}_{2}, \mathrm{CH}_{4}$, and NOx emissions per year by $54 \mathrm{tCO}_{2} \mathrm{eq}, 40 \mathrm{kgCO}_{2} \mathrm{eq}$, and $60 \mathrm{kgCO}_{2}$ eq respectively of which the contribution of $\mathrm{CO}_{2}$ is significant.

The information discovered in this study will be useful for the national energy and environmental regulatory team of a developing country to develop the energy and environmental planning in target to reduce national energy consumption and environmental emission.

\section{Acknowledgment}

Uddin would like to thank the Department of Mechanical Engineering of Rajshahi University of Engineering \& Technology (RUET) for providing the platform for this work. Thanks to those who directly or indirectly contributed to completing this work. There is no direct funding for this work and there is no conflict of interest.

\section{References}

[1] Desai N. Searchlight South Asia: The Auto Rickshaw Diaries. The alternative India 2013; [updated August 2017]: Available from: https://www.thealternative.in/society/

[2] Rian MZ, Rahman ANM. Study on power consumption and social aspects of battery-operated Auto-rickshaw. Proceedings to the International Conference on Mechanical, Industrial and Energy Engineering. Khulna, Bangladesh, 2014.

[3] Joe Cackler, Emily Gu, and Mike Rodgers. Technology in developing economies, 2008. https://cs.stanford.edu/people/eroberts/ cs181/projects/2007-08/developing-economies/

[4] John A. Mathews. Developing countries and the renewable energy revolution, 2016. https://www.oecd.org/fr/dev/developing-countriesand-the-renewable-energy-revolution.htm

[5] Mankar PM, Ghute AA. Solar-powered battery-operated electric vehicle as an option for fueled vehicle. Int J Eng Sci Res Technol 2015; 4(4): 425-429.

[6] Ahmed SR, Zeshan SQ, Kamdod ASM. Solar rickshaw for sustainable energy future. Int J Curr Eng Scienti Res 2015; 2(12): 91-93.

[7] Rian MZ, Rahman ANMM. Study on power consumption and social aspects of battery operated auto-rickshaw. International Conference on Mechanical, Industrial and Energy Engineering (ICMIME). Department of Mechanical Engineering,Khulna University of Engineering \& Technology, Khulna, Bangladesh, 2014.

[8] Rana MS, Hossain F, Roy SS, Mitra SK. Energy consumption by battery operated auto rickshaw. Daffodil Int Univ J Sci Technol 2013; 8(2): 71-76.

[9] Shaha N, Uddin MB. Hybrid energy modeling for auto vehicles. International Conference on Mechanical, Industrial and Energy Engineering (ICMIME). Electrical and Electronics Engineering Department, Dhaka University of Engineering and Technology, Gazipur, Bangladesh, 2013.

[10] Rahim MA, Joardder MUH, Hoque SMN, Rahman MM, Sumon NH. Socio-economic and environmental impacts of battery-driven autorickshaw at Rajshahi city in Bangladesh. International Conference on Mechanical, Industrial and Energy Engineering (ICMIME). Department of Mechanical Engineering, Rajshahi University of Engineering \& Technology, Rajshahi, Bangladesh, 2013. 
[11] Nunes P, Figueiredo R, Brito MC. The use of parking lots to solar-charge electric vehicles. J Renewable and Sustainable Energy Rev 2016; 66(1): 679-693. https://doi.org/10.1016/j.rser.2016.08.015

[12] Muzzammir M, Abdullah AMF. An Economic Analysis of Solar PV System in Bangladesh. Department of Electrical and Electronics Engineering, Daffodil International University, Bangladesh 2014; 1-87.

[13] Bangladesh Power Development Board. Generation of power, November-2017. https://www.bpdb.gov.bd/

[14] Darío RG, John DW, Branca BA, Chia H, Gregg M, Emmanuel M, et al. Stationary Combustion: Chapter 2. 2006 IPCC Guidelines for National Greenhouse Gas Inventories, 1-47.

[15] Pachauri RK, Meyer L. Climate Change 2014 Synthesis Report. USA: IPCC, 2015. 